DOI 10.37882/2500-3682.2020.12.12

\title{
К ВОПРОСУ О СУБСТИТУЦИИ ТЕРМИНА «СИНКРЕТИЗМ»
}

\section{TO THE QUESTION ABOUT THE SUBSTITUTION OF THE TERM "SYNCRETISM»}

\section{Efimov}

Summary: The article analyzes the term and concept of religious syncretism. Proceeding from the expediency of achieving terminological accuracy, the author draws attention to the fundamental characteristic of the syncretization process, seen in the acceptance (reception) of foreign religious elements. In this regard, and also taking into account the historical fact that the term "syncretism» acquired pejorative connotations, the prospect of terminological substitution is discussed, argued by its bidirectional potential, which consists in increasing the nominative-definitive adequacy and eliminating terminological incorrectness as a conflict-generating factor.

Keywords: religious syncretism, interreligious relations, terminology of religious studies, intercultural interaction, syncretization, reception.

\author{
Ефимов Денис Александрович \\ Соискатель, ФГАОУВО «Дальневосточный \\ федеральный университет» \\ lawyerefimov@gmail.com
}

Аннотация: В статье анализируются термин и понятие религиозного синкретизма. Исходя из целесообразности достижения терминологической точности, автор обращает внимание на принципиальную характеристику процесса синкретизации, усматриваемую в принятии (рецепции) инорелигиозных элементов. В связи с этим, а также учитывая исторический факт обретения термином «синкретизм» пейоративных коннотаций, обсуждается перспектива терминологической субституции, аргументируемая ее двунаправленным потенциалом, заключающимся в повышении номинативно-дефинитивной адекватности и элиминации терминологической некорректности как конфликтогенного фактора.

Ключевые слова: религиозный синкретизм, межрелигиозные отношения, терминология религиоведения, межкультурное взаимодействие, синкретизация, рецепция.

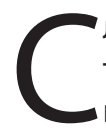

лово «синкретизм» известно с античных времен. В трактате «О братской любви» Плутарх писал о синкретизме как термине, которым именовали свое объединение пред лицом общего врага жители о. Крит

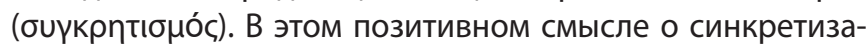
ции говорил и Эразм Роттердамский (в послании Филиппу Меланхтону), демонстрируя преимущества конкордации.

Однако уже к XVII веку развилось определенное семантическое смещение (отраженное, в частности, в «Ирениконе» Эрберманна, изданном в 1645 году), в результате которого синкретизм приобрел смысл «незаконного» религиозного смешивания. Поздняя этимологизация, альтернативная представленной Плутархом, по-видимому, поддерживает этот смысл: слово «синкре-

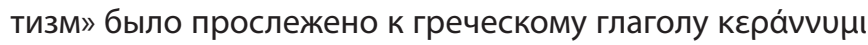
(смешивать) и производному существительному кра̃бıৎ (смешение) с префиксом бuү (вместе), соединение которых мы также наблюдаем в слове «идиосинкразия» [21, p. $3 ; 14$, р. 240]. Данная этимология, впрочем, не бесспорна, и неубедительность доводов, выдвигаемых в ее поддержку, аргументированно показана, в частности, И.А. Левинской [9, с. 563]. Ранее Ф.Ф. Зелинский также обращал внимание на то, что в XVI-XVII веках первоначальный смысл обсуждаемого термина еще не был забыт, но утратился «после его перемещения в религиоведение в общем, поскольку неучи сближали его... с греческим

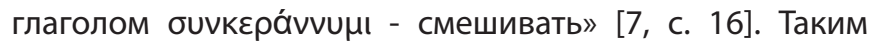
образом, тогда как некоторые авторы, как, например, ч. Стюарт, прослеживают происхождение слова «синкре- тизм» к греческому «смешиванию», для Ф. Ф. Зелинского подобная этимологизация являлась признаком «неуча».

Многие исследователи (антропологи, культуроведы, религиоведы, теологи) признают наличие негативных коннотаций в термине «синкретизм». Так, К. Рудольф отмечал, что это слово, по сути, стало «теологическим оскорблением» [19, р. 69]. Оно подразумевает уничижительную коннотацию несовместимости [16, р. 92; 15, р. 163], создает впечатление, что речь идет «о лоскутном одеяле, бриколаже, странной агломерации» [12, р. 91-92], содержит евроцентристские предубеждения и является пренебрежительным [17, р. 9]. Применительно к афрогенным культам в понятии синкретизма также обнаруживаются «следы неоколониализма, расизма и притеснения» [13, р. 37].

С исторической и теологической точек зрения обсуждаемый термин был подвергнут основательной критике Р. Бэрдом. Он отметил, что в историческом смысле данное понятие «не служит никакой полезной цели», поскольку одинаково применимо ко всем религиям, и, следовательно, его использование для дескрипции «не говорит нам ничего конкретного». Иными словами, сказать, что некая религия синкретична, «значит, не сказать ничего», поскольку такое обозначение не указывает на какой-либо признак, отличающий эту религию от других. В связи с этим автор предложил «отказаться от термина «синкретизм» как обозначения исторического явления» [11, p. 50-52]. 
Приведенный довод оспорил М. Пай. Он указал, что «аргумент содержит логическую ошибку, поскольку, хотя верно, что все религии синкретичны, это не единственное, что можно о них сказать». Ценность же данного термина как раз и заключается в акценте на обозначаемом им аспекте всех религий. Кроме того, выдвигая данный аргумент, Р. Бэрд, «вопреки его намерениям», де-факто сам признал «важность синкретизма» как «значимого аспекта религиозных процессов» [18, р. 221]. На наш взгляд, несмотря на достаточную аргументированность изложенной критики, позиция М. Пая выглядела бы более основательной, если бы намерением Р. Бэрда действительно являлось отрицание наличия или значимости процессов, именуемых синкретизмом, а не анализ и критика указанного термина и понятия.

Аргументируя перспективы использования термина в теологическом контексте, Р. Бэрд обсуждает критерий гармоничности единства, когерентности синкретизированных элементов. Так, если говорится, что синкретизм - это смесь/соединение в гармоничное целое несовместимых или противоречивых элементов (как, например, компромисс между «противоположными и абсолютно противоречивыми» практиками и учениями [20, р. 21-22]), то такое суждение является контрадикторным, поскольку говорит о согласованности противоречивого. Если элементы согласованы в гармоничном целом, то их противоречивость была лишь кажущейся либо устранилась их модификацией. Отсюда Р. Бэрд приходит к выводу, что термин синкретизм может быть использован только в тех случаях, когда мы имеем дело с объединением разнорелигиозных элементов в «новый комплекс», лишенный когерентности, «гармоничного единства» $[11$, р. 52-53, 56].

Соглашаясь с другими доводами Р. Бэрда, отметим спорность предложенного им понимания гармоничности как критерия. Дело в том, что методологический аппарат религиоведения не располагает, так сказать, «гармониметром», и мы лишь весьма субъективно можем решать, где присутствует или отсутствует «гармоничное единство» синкретизированных элементов. Кроме того, как было отмечено, «наличие противоречащих друг другу элементов... является нормой» для всех живых религий и религиозных систем, «и нет нужды поэтому вводить особый термин [синкретизм] для обозначения этого явления» [1, с. 181]. И, наконец, как верно указал сам Р. Бэрд, хотя мы и можем увидеть некогерентность в синкретической религии, ее гетерогенные элементы вполне когерентны в глазах адептов. Поэтому неудивительно, что термин «синкретизм» обычно «не используется верующим для описания своей религии», но употребляется тем, кто не принадлежит ей, и потому «не видит» или не ощущает «ее внутреннее единство». Таким образом, «единственное законное использование» данного термина, по мнению Р. Бэрда, не только «теологи- чески неприменимо» к описанию конкретной религии, но и является «барьером» для ее понимания. Если же мы стремимся «прийти к пониманию веры других людей, крайне важно избегать этого термина», который к тому же содержит пейоративные коннотации $[11$, р. 50, 54, 56-57].

Возражая Р. Бэрду, К. Рудольф отмечает, что, вопервых, «пейоративный смысл синкретизма» обнаруживает лишь тот, «кто использует этот термин в обычном теологическом смысле и не способен согласиться с его нейтральным использованием в религиоведении», а, вовторых, верующие вполне могут рассматривать свою религию как синкретическую (как это, например, неоднократно делали даже христианские теологи) [19, р. 73]. По нашему мнению, аргументация К. Рудольфа хотя и верна, но не приводит к устранению проблемы. Разумеется, вполне возможно говорить о синкретизме нейтрально, без предубеждений и т.п. И, конечно, не всякий, кто обозначает некую религию «синкретической», руководствуется идеями евроцентризма или выражает уничижительное, пренебрежительное или оскорбительное отношение к ней, равно как и не каждый адепт той или иной религии воспринимает слово «синкретизм» как пейоратив. В то же время, поскольку сам термин имеет по меньшей мере одно (теологическое) негативное значение (о чем еще будет сказано ниже) и ряд широкоизвестных негативных коннотаций (которые мы упомянули выше), использующий его религиовед либо понуждается так или иначе оговаривать свою и термина нейтральность, либо рискует быть понятым как тот, кто использует дерогатив. Факт остается фактом - многие последователи принципиально не приемлют приложение термина «синкретизм» к исповедуемым и практикуемым ими религиям. Сколько христиан или мусульман согласятся с тем, что их религии являются синкретическими, пусть даже и в нейтральном смысле данного термина?

Конечно, верно, что религиовед не должен рассматривать мнение последователей некой религии в качестве критерия правильности своих научных суждений, но должен «следовать своим собственным историко-критическим методам» $[19$, р. 72]. Однако если речь идет о неоднозначном термине, имеющем негативные коннотации (пусть и не подразумеваемые в конкретном случае самим говорящим), которые, как было отмечено, оскорбительны для религиозных чувств верующих, то его употребление требует осмотрительности. Религиозная сфера является весьма чувствительным сегментом общественной жизни, а дерогативы, как указал А.В. Гладилин, «есть маркеры языка вражды» [4, с. 131]. С последним определением можно согласиться, имея в виду, что использование «стигматизирующих» терминов, тем более имеющих пейоративные коннотации, отнюдь не способствует консолидации мультирелигиозного общества, мирному межрелигиозному диалогу и сосуществованию. 
Необходимо также отметить, что в целях элиминации негативных коннотаций термина «синкретизм» рядом авторов осуществлялись попытки научной ревизии самого понятия. Однако, несмотря на все усилия, «последствия истории данного понятия сохраняются в сознании последователей различных традиций, являющихся частью христианского мира или контактирующих с ним» $[16$, p. 8]. Данный факт признается и во Всемирном совете церквей (далее - ВСЦ), где констатируют, что, «несмотря на попытки спасти слово «синкретизм»», оно все еще несет негативный смысл и отвергается многими «партнерами по диалогу» («Guidelines on Dialogue with People of Living Faiths and Ideologies», п. 26).

Ревизия обсуждаемого термина в значительной степени затрудняется и тем, что христианские конфессии, имея на то собственные основания, продолжают рассматривать синкретизм как нечто опасное или предосудительное. Так, пункты 27 и 28 процитированного документа говорят об «опасностях» синкретизма. Католическая церковь, представленная в ВСЦ в качестве наблюдателя, в свою очередь отвергает «всякую разновидность синкретизма» в пункте 22 Декрета «К народам» Второго Ватиканского собора [5, с. 384]. Данный подход, разумеется, не может не оказывать влияния на миллионы христиан, являющихся членами этих церквей. В связи с этим негативность синкретизма, с одной стороны, все еще сохраняется в сознании многих верующих, а с другой стороны, распространяется и за пределы христианского контекста, негативируя понимание синкретизма нехристианами.

Что касается сущности синкретизма, то при анализе его дефиниций можно обнаружить множественность подходов к осмыслению данного явления. В отечественной науке, в частности, известно определение Н. С. Капустина, который понимал синкретизм как «объективный процесс соединения, слияния различных религиозных элементов, верований и культов в ходе их взаимодействия друг с другом и образования новой, целостной системы мировоззрения, мироощущения и культа со своей специфической структурой» [8, с. 13]. Данное определение, однако, вряд ли можно назвать точным, поскольку синкретизация отнюдь не обязательно должна приводить к появлению «целостной системы мировоззрения, мироощущения и культа» (даже если бы мы имели некий методологический инструмент для измерения «целостности»), и отсутствие именно такого результата никак не препятствует идентификации «соединения, слияния различных религиозных элементов» как «синкретического».

Другие авторы видели сущность религиозного синкретизма в транспозиции (Герард ван-дер-Леу), алиенации (Ж. Камстра), осмическом сплетении разнорелигиозных элементов (К. Рудольф), интерпенетрации (А. Дрогерс), комбинации (Ч. Стюарт), временной неодно- значной коэкзистенции (М. Пай), заимствовании, аффирмации, интеграции (Дж. Берлинг) и т. д. Для иных же, как указывают исследователи, «уже только факт наличия этнокультурных контактов оказывается достаточным основанием для постулирования религиозного синкретизма» $[9$, с. 565], и синкретизмом считается даже «всякое сближение» религий [10, с. 3].

Как отмечает Ю.В. Гаврилова, именно трудности определения сущностных характеристик синкретизма являются одной из причин, по которым некоторые исследователи отказываются использовать это понятие [3, с. 86]. Действительно, при ближайшем рассмотрении можно увидеть, что отчуждение, к примеру, вряд ли можно назвать чертой всякого синкретизма, поскольку оно не всегда сопровождает его (нередко инорелигиозные элементы лишь прибавляются к имеющимся без отчуждения реципиентом чего-либо), равно как и одно лишь «прибытие» чуждых элементов не всегда приводит к синкретизации. Заимствование также не является отличительным признаком синкретизма, поскольку предполагает наличие акта воли заемщика, тогда как в случаях асимметричных межкультурных взаимоотношений инорелигиозные элементы могут быть, по сути, навязаны. Так, например, африканские рабы в колониальных условиях не всегда могли открыто исповедовать и практиковать свои африканские религии, но часто были вынуждены скрывать их под католическими масками. Проблематично и понимание синкретизма как изменения значения при неизменности формы, поскольку данная редукция рестриктивно исключает те случаи синкретизма, в которых форма претерпевает изменения или значение остается неизменным. Что касается интерпенетрации, подразумевающей взаимопроникновение, можно обратить внимание на то, что процессы синкретизации отнюдь не всегда являются обоюдными, взаимными, но нередко имеют одностороннюю направленность (одна религия принимает элемент из другой, которая, однако, ничего не принимает из первой).

Многие иные определения (сплетение, скрещивание, комбинация, коэкзистенция, интеграция и т.п.) в большей мере указывают на различные уровни, формы или степени соединения или соприсутствия синкретизируемых элементов в реципирующей религии, т.е. обозначают вторичные процессы или их результаты. Все они следуют за принятием реципиентом инорелигиозных элементов. Никакой синкретизм не возникнет, если инорелигиозный элемент не был принят (реципирован). По этой причине нельзя и постулировать синкретизм в простом сближении или контакте культур.

Таким образом, сущностным признаком синкретизма можно считать принятие представителями одной религии элементов иной религии. Лишь убедившись, что такой элемент принят (даже если не вполне осознанно или 
недобровольно), возможно говорить о явлении, именуемом синкретизмом. Следовательно, понятие рецепции инорелигиозных элементов вполне отражает первую и главную характерную черту процесса синкретизации.

Не являющийся новым термин «рецепция», содержащийся в качестве научного слова (наряду с глаголом «реципировать» и причастием «реципированный») в третьем томе Толкового словаря русского языка Д.Н. Ушакова (изданном в 1939 году), используется и теологами. Так, в своей «Апологетике» (Париж, 1957) В. В. Зеньковский объяснил принцип рецепции в его православном понимании: «Христианин, живущий «обновленным умом»... может смело и безбоязненно принимать все из язычества, что остается неизмененным при освещении его светом Христовым». При этом автор подчеркивает, что процесс реципирования «менее всего может быть уподобляем известному уже нами явлению синкретизма в языческом религиозном сознании», и характеризует синкретизм как «срастание, сгущение различных верований». Таково православно-богословское понимание рецепции.

Западные теологи, в свою очередь, обсуждают проблему дифференцирования приемлемой инкультурации/контекстуализации и неприемлемого синкретизма [23, p. 82-83; 15, р. 175], которая, на наш взгляд, также во многом обусловлена негативными коннотациями и теологической нагруженностью термина «синкретизм» (в связи с чем немногие согласятся, что их религия синкретична). Это хорошо проиллюстрировал Ч. Стюарт, приведя распространенное среди многих верующих убеждение, согласно которому только «другие религии являются синкретическими, но не наша» [22, р. 277]. Таким образом, в то время как научная объективность заставляет признать, что, «строго говоря, все религии генетически гетерогенны и, следовательно, синкретичны» [9, с. 563], складывается ситуация, когда исторический факт гетерогенности религии противостоит вполне объяснимому нежеланию верующих признать историческую «синкретичность» собственной религии.

Несмотря на использование термина «рецепция» в восточной и западной теологии, в более широком, конфессионально необусловленном контексте, не имеется препятствий для его употребления в качестве обозначения принятия инорелигиозных элементов как такового. Другими словами, сам по себе факт задействования в конкретной конфессиональной теологии некоего термина (в определенном его смысле) еще не является достаточным основанием для отказа от его использования во внеконфессиональной сфере, в иных терминосистемах. Более того, в XX веке понятие рецепции (в его соответствующих дисциплинарно-терминологических особенностях) получило достаточно широкое распространение в философии, литературоведении, культурологии, юриспруденции и т. д. Используют его и российские ученые, изучающие межкультурные и межрелигиозные взаимодействия. Так, диссертация Е. В. Кожевановой, защищенная в 2007 году по теории и истории культуры, посвящена теме рецепции мусульманской ментальности в русско-советской культуре XX века. В рамках философии религии и религиоведения А.А. Жукова писала об особенностях рецепции буддийских идей русскими Забайкалья [6], защитив в 2013 году диссертацию по данной теме. Немногим ранее, в 2010 году, Т.В. Бернюкевич, несколько публикаций которой также были посвящены именно рецепции буддийских идей в философии и культуре России, защитила докторскую диссертацию по теме «Буддийские идеи в культуре России конца XIX - первой половины XX века».

Говоря о перспективе терминологической субституции, нужно отметить, что она заключается не только в достижении большей терминологической точности отражения существа обсуждаемого явления, но имеет и определенный праксеологический потенциал в реалиях мультирелигиозного и мультиконфессионального социума, стремящегося к устранению причин и условий, способствующих возникновению межрелигиозных конфликтов и розни. Действительно, тезис «ни одна из религий не избежала рецепций» вряд ли вызовет отторжение или когнитивный диссонанс у последователя постулируемо несинкретической религии, в то время как тот же самый тезис, выраженный с использованием слова «синкретизм», может иметь существенный конфликторный потенциал и восприниматься адресатом резко негативно (применительно к его собственной религии). Если для христианина разница между христианской и «языческой» рецепцией заключается в ее качествах (принятие того, «что остается неизмененным при освещении его светом Христовым» для христианина качественно отличается от «языческой» рецепции, понимаемой как срастание или сгущение верований), то представители иных религий, разумеется, могут иметь собственное мнение о качествах и критериях допустимости возможного реципирования. Существо же самого явления (процесса и его результата) остается одним и тем же - принятием инорелигиозных элементов. А если это так, то вполне оправданным (особенно во внеконфессиональном научном контексте) представляется использование термина, который буквально и означает то, о чем мы говорим («принятие»), более точно отражая суть обозначаемого им явления, и не имеет при этом негативных или оценочных коннотаций.

Обсуждая проблемы, присущие термину «синкретизм», И.А. Левинская замечает, что «этимологическая некорректность... еще не служит достаточным основанием для того, чтобы от него отказываться - в противном случае нам пришлось бы серьезно пересматривать научную лексику» [9, с. 562]. Это справедливое замечание. 
Вместе с тем «этимологическая некорректность» - далеко не единственный мотив для пересмотра обсуждаемого термина. Так, подвергая критике понятие синкретизма в гуманитарных науках, А.Н. Анфертьев также подробно аргументировал «несостоятельность понятия «синкретизм» для религиоведческой области с точки зрения как истории, так и логического содержания термина...» [1, с. 182]. Кроме того, представляются дискуссионными как конвенциональность и научность обсуждаемого термина (даже принимая во внимание его определенную внедренность и интернациональность), так и зависимость от него стабильности научной лексики.

Как небезосновательно полагает Е.И. Аринин, «религиоведческая методология должна опираться не только на термины самоописания конфессий и религиозных объединений, но и создавать особый «метаязык» второго порядка, отстраненный от самой непосредственной религиозной жизни» [2, с. 28]. Однако вряд ли в терминосистему такого языка «второго порядка» нам следует ввести (или сохранить в ней) слово «синкретизм». История данного термина показывает, что в научную (прежде всего, религиоведческую) лексику он проник непосредственно из теологических споров о, так сказать, чистоте и смеси. Причем не только проник, но и принес с собой известный пейоративный шлейф. Теологическая же некорректность термина даже побудила Ф.Ф. Зелинского жестко потребовать, «чтобы этот идиотский [термин] синкретизм был полностью изгнан» [7, с. 16]. Конечно, столь категоричная позиция уважаемого академика не имела и не может иметь императивного характера для научного сообщества, но вопрос, по крайней мере, заслуживает обсуждения. Кроме того, как верно заметил Р. Бэрд, значение, которое вкладывают в термин «синкретизм», зачастую могло бы быть выражено более ясно, если бы использовался другой термин [11, р. 48]. И если имеется или может быть подобран термин, который и не имеет коннотаций, оскорбительных для религиозных чувств верующих, и более адекватен обозначаемым им реалиям, то представляется целесообразным его использование с тем, чтобы достичь большей терминологической точности и устранить терминологический фактор конфликтогенности.

\section{ЛИТЕРАТУРА}

1. Анфертьев, А.Н. К вопросу о религиозном синкретизме / А.Н. Анфертьев // Известия Общества археологии, истории и этнографии при Казанском университете. - 2017. - № 1. - С. 178-183.

2. Аринин, Е.И. Философия религии. Принципы сущностного анализа : монография / Е.И. Аринин. - Архангельск: Изд-во Поморского государственного университета им. М.В. Ломоносова, 1998. - 297 с.

3. Гаврилова, Ю.В. Современный религиозный синкретизм: факторный анализ трансформации религиозного сознания: монография / Ю.В. Гаврилова. Чита : ЗабГУ, 2018. - 238 с.

4. Гладилин, А.В. 0 биокультурной природе дерогативов // «Сибирское медиапространство 2020» : Материалы I междисциплинарной научно-практической конференции с международным участием (26-27 марта 2015 г.) [Электронный ресурс] / Сост. К.А. Зорин, М.Л. Подлубная, В.И. Тармаева. - Красноярск: Сибирский федеральный университет, 2015. - С. 131-134. - URL: http://conf.sfukras.ru/uploads/sibirskoe\%20mediaprostranstvo\%202020.pdf (дата 06ращения: 13.11.2020).

5. Документы II Ватиканского собора / [пер. А. Коваля; ред. В. Шайкевич]. - Москва: Паолине, 1998. - 589 с.

6. Жукова, А.А. Особенности рецепции буддийских идей русскими Забайкалья в XX в. / А.А. Жукова // Вестник Забайкальского государственного университета. - 2013. - № 3. - С. 111-118.

7. Зелинский, Ф.Ф. История античных религий. Том 5, кн. 1 / Ф.Ф. Зелинский; пер. с польск. И. Бея. - Санкт-Петербург: Издательский проект «Квадривиум», 2018. $-400 \mathrm{c}$

8. К Капустин, Н.С. Особенности эволюции религии (на материалах древних верований и христианства) / Н.С. Капустин. - Москва : Мысль, 1984. - 222 с.

9. Левинская, И.А. Синкретизм: термин и феномен / И.А. Левинская // Страницы: богословие, культура, образование. - 1998. - Т. 3, № 4. - С. $558-567$.

10. Селезнёв, А.Г. Сибирский ислам: региональный вариант религиозного синкретизма / А.Г. Селезнёв, И.А. Селезнёва. - Новосибирск: Институт археологии и этнографии СО РАН, 2004. - 72 c.

11. Baird, R.D. Syncretism and the History of Religions / R.D. Baird // Syncretism in Religion: A Reader / A.M. Leopold, J.S. Jensen (eds.). - New York: Routledge, 2005. - P. 48-58.

12. Ferretti, S.F. Religious Syncretism in an Afro-Brazilian Cult House / S.F. Ferretti // Reinventing Religions: Syncretism and Transformation in Africa and the Americas / S.M. Greenfield, A. Droogers (eds.). - Lanham, Boulder, New York, Oxford: Rowman \& Littlefield, 2001. - P. 87-97.

13. Heideman, E.S. Syncretism, Contextualization, Orthodoxy and Heresy / E. S. Heideman // Missiology: An International Review. - 1997. - Vol. 25, № 1. - P. 37-49.

14. Hoskins, J.A. The Divine Eye and the Diaspora: Vietnamese Syncretism Becomes Transpacific Caodaism / J.A. Hoskins. - Honolulu : University of Hawai'i Press. 2015. $-X V I I I, 283 p$.

15. Jørgensen, J.A. Khrist Bhaktas and the Reconstruction of Syncretism / J.A. Jørgensen // Theological and Philosophical Responses to Syncretism: Beyond the Mirage of Pure Religion / P. Fridlund, M. Vähäkangas (eds.). - Leiden, Boston : Brill, 2017. - P. 163-177.

16. Leopold, A. Syncretism in Religion: A Reader / A. Leopold, J.S. Jensen (eds.). - New York : Routledge, 2005. - 402 p. 
17. Olmos, M.F. Creole Religions of the Caribbean: An Introduction from Vodou and Santeria to Obeah and Espiritismo / M.F. Olmos, L. Parvisini-Gebert. - New York : New York University Press, 2011. - xi, 309 p.

18. Pye, M. Syncretism versus synthesis / M. Pye // Method \& Theory in the Study of Religion. - 1994. - Vol. 6, № 3. - P. $217-229$.

19. Rudolph, K. Syncretism: from theological invective to a concept in the study of religion / K. Rudolph // Syncretism in Religion: A Reader / A.M. Leopold, J.S. Jensen (eds.). - New York : Routledge, 2005 - - P. 68-87.

20. Sahay, V.S. Syncretism in India: A Reality or an Unreality? / V.S. Sahay // The Oriental Anthropologist. - 2016. - Vol. 16, № 1. - P. $17-25$.

21. Shaw, R. Introduction: problematizing syncretism / R. Shaw, Ch. Stewart // Syncretism/Anti-Syncretism : The Politics of Religious Synthesis / Ch. Stewart, R. Shaw (eds). - London, New York: Routledge, 1994. - P. 1-24.

22. Stewart, Ch. Relocating Syncretism in Social Science Discourse / Ch. Stewart // Syncretism in Religion: A Reader / A.M. Leopold, J. S. Jensen (eds.). - New York: Routledge, 2005. - P. 264-285.

23. Vähäkangas, M. Theo-Logical Positions vis-à-vis Syncretism / M. Vähäkangas // Theological and Philosophical Responses to Syncretism: Beyond the Mirage of Pure Religion / P. Fridlund, M. Vähäkangas (eds.). - Leiden, Boston: Brill, 2017. - P. 68-87.

(c) Ефимов Денис Александрович (awyerefimov@gmail.com).

Журнал «Современная наука: актуальные проблемы теории и практики»

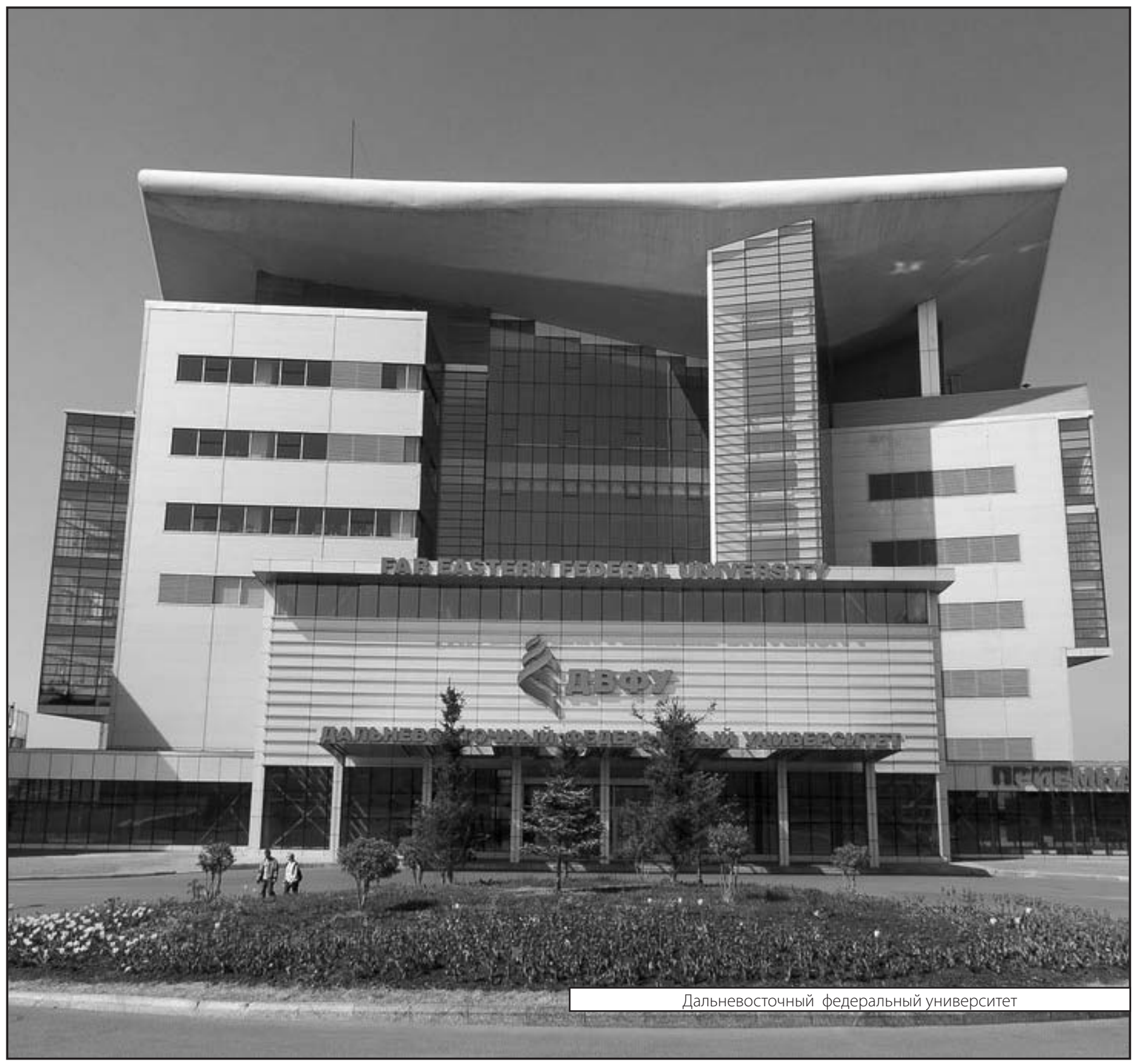

